\title{
AVALIAÇÃO DA DURAÇÃO DAS VIDEOAULAS NA PERSPECTIVA DOS ALUNOS DO CONSÓRCIO CEDERJ
}

\author{
RIO DE JANEIRO/RJ JULHO/2018 \\ $\begin{array}{cc}\text { Clarisse de Mendonça e Almeida } & \text { - Cederj - cmalmeida@cecierj.edu.br } \\ \text { Nathalia Alves de Carvalho } & \text { - UFRJ - alves.nathalia.c@gmail.com }\end{array}$ \\ Tipo: Investigação Científica (IC) \\ Natureza: Descrição de Projeto em Andamento \\ Categoria: Métodos e Tecnologias \\ Setor Educacional: EDUCAÇÃO SUPERIOR
}

\begin{abstract}
RESUMO
Reconhecendo as videoaulas como relevantes ferramentas educacionais no processo de ensinoaprendizagem dos cursos semipresenciais e a distância, o presente artigo se propõe a discutir a relação entre a duração desses materiais audiovisuais e a retenção da atenção dos alunos no momento em que estudam. Tendo como base o levantamento feito - por meio de um questionário junto a alunos dos cursos de graduação semipresenciais de Administração, Pedagogia e Tecnólogo em Segurança Pública e os dados coletados no Youtube Analytics sobre as videoaulas produzidas pelo Consórcio Cederj, o que se busca é compreender e estabelecer o tempo ideal de duração das videoaulas na visão dos discentes. Espera-se que tal discussão funcione como uma diretriz para o trabalho de designers instrucionais de modo a tornar as videoaulas uma ferramenta educacional mais atrativa para os alunos, diminuindo possíveis distrações e desistências ao longo do percurso do estudo. Embora assumam um papel relevante no universo do ensino a distância, ainda pouco se discute teoricamente sobre as videoaulas e sua aplicação prática pela perspectiva do aluno - viés esse a ser abordado no presente artigo. Como referenciais teóricos, esse estudo busca apoiar-se, entre outros, em autores como Kenski (2016) ao reconhecer as videoaulas como dinamizadoras do espaço de ensino-aprendizagem, em Barrére (2014) quando afirma que tais ferramentas potencializam as oportunidades de mediação pedagógica e em Tori (2016) ao afirmar que o conteúdo para estudo em videos representa atualmente o recurso dominante nos cursos a distância.
\end{abstract}

Palavras-chave: vídeo; educação; educação à distância; EaD; youtube

\section{AGRADECIMENTOS}

À FUNDAÇÃO CECIERJ E AOS COORDENADORES DE CURSO E DISCIPLINA QUE SEMPRE APOIARAM AS PESQUISAS ACADÊMICAS. 


\section{Popularização das videoaulas}

Planejadas como um recurso educacional no momento de enriquecer as salas de aulas dos cursos oferecidos nas modalidades semipresenciais e a distância, as videoaulas se popularizaram e conquistaram o reconhecimento de docentes e alunos que veem nesses materiais uma possibilidade a mais na compreensão os conteúdos. Por representar para muitos como "entretenimento", as videoaulas se propõem a quebrar a aridez do processo de ensino-aprendizagem ao combinar linguagem coloquial e mix de imagens, narrações e ritmos podendo, se caso bem construído, se firmar como um importante aliado no momento do estudo. A multiplicidade de formatos e narrativas possíveis torna as videoaulas ainda mais atraentes cabendo ao docente optar pelo seu uso, ou não, sempre em consonância com as demais estratégias escolhidas para a transmissão de determinado conteúdo podendo funcionar como um elemento problematizador acerca de um tema, incitando reflexões e contribuições.

No modelo da Educação a Distância, onde comumente alunos apontam a solidão e a separação física no espaço e no tempo (MOORE, 2002) como um dos principais motivos para a evasão dos cursos, as videoaulas transmitem certo conforto e acolhimento ao apresentar conteúdos por meio de um formato mais próximo de uma "conversa" do que de uma aula mais formal. Mesmo utilizando-se de uma tecnologia por meio da qual a interação é assíncrona, ou em que não há interação, tal recurso ganha ainda mais força justamente ao unir a imagem do professor a "uma riqueza de detalhes gerando uma maior compreensão dos alunos com relação aos conteúdos ali retratados" (SPANHOL, 2009).

A facilidade na edição, busca e compartilhamento de vídeos na web e a popularização de tecnologias móveis (celulares, tablets...) potencializam o uso do recurso para fins educacionais podendo ser explorado principalmente pelos designers instrucionais no momento de planejamento das estratégias educacionais para os cursos em conjunto com os docentes. Na ausência do efetivo acompanhamento dos designers instrucionais, os vídeos "caseiros", amadores, se mostram como uma alternativa aos docentes interessados em divulgar o conteúdo de suas aulas, sendo de fácil manipulação e baixo custo. Para Mattar (p.4, 2009), "é preciso superar o receio do uso do vídeo amador em educação, inclusive porque os usuários (nossos alunos) já estão acostumados e sensibilizados com essa nova mídia". O recurso amador ganha ainda mais força justamente ao se ajustar à realidade de popularização de webcams, smartphones e notebooks onde cada um produz seu próprio conteúdo educacional e o disponibiliza, em seguida, nas plataformas gratuitas. 
Embora populares nos cursos ofertados a distância, as videoaulas representam um recurso ainda pouco debatido no que se refere à percepção dos alunos acerca do uso destes materiais. Sendo assim, o presente trabalho tem como objetivo principal trazer à tona um recorte dessa discussão ao investigar qual seria, na visão dos discentes, o tempo de duração ideal para as videoaulas - disponíveis nos canais dos cursos do Youtube. Para investigar a visão dos discentes foi enviado um questionário aos alunos dos cursos de Administração (UFRRJ), Tecnólogo em Segurança Pública (UFF) e Pedagogia (UniRio), geridos pelo Consórcio Cederj. Associado a esses resultados, buscou-se, por meio da ferramenta Youtube Analytics perceber qual o tempo de retenção da atenção dos alunos de modo a comparar com os resultados compilados pelo questionário e perceber, assim, se, de fato, a opinião dos alunos coincide com a capacidade de retenção observada. Acredita-se que tal problematização possa ser relevante na medida em que os resultados aqui levantados possam orientar docentes e designers instrucionais no planejamento de uso destes materiais.

As discussões aqui levantadas apoiam-se em autores renomados nesse campo teórico como Prensky (2012) - ao levantar questões acerca dos nativos digitais e sua relação com a tecnologia, em especial, com os dispositivos móveis e manipulação de sites e aplicativos -, Tori (2016), Mattar (2009) e Barrére (2014), entre outros, ao reconhecerem a relevância das videoaulas como um recurso didático eficiente para a assimilação do conteúdo e o acolhimento dos alunos em cursos oferecidos a distância.

\section{Videoaulas na web}

No cenário de popularização e potencialização dos materiais audiovisuais como recursos educacionais, instituições de ensino constroem seus canais e disponibilizam suas videoaulas nos diversos repositórios de mídias gratuitos hoje disponíveis. Criado em 2005, o Youtube firmou-se, aos poucos, como um espaço fundamental para o compartilhamento desses materiais, tanto pela sua popularidade crescente como pela facilidade no acesso e no manuseio da ferramenta e ainda pela possibilidade de convergência com outras mídias sociais (Facebook, Twitter...). Ali, estão disponibilizadas videoaulas produzidas tanto de forma "caseira" pelos próprios docentes ou alunos quanto materiais audiovisuais construídos por uma equipe multidisciplinar formada por designers instrucionais, editores de imagens e áudio, entre outros profissionais. A autora De Quadros (2013) reafirma o potencial pedagógico do Youtube:

\footnotetext{
"Ao agregar informações sobre determinado tema de estudo, seja em forma de vídeo ou até mesmo num comentário sobre ele, ideias podem ser discutidas para refletir sobre os mais variados temas e, assim, contribuir para a produção de conhecimento" (De Quadros, 2013, p.8).
} 
Embora se reconheça a facilidade, e até naturalidade, com que os nativos digitais (PRENSKY, 2012) manipulam os recursos tecnológicos, tutoriais de linguagem simples e acessível disponíveis no próprio Youtube orientam os usuários a disponibilizar e compartilhar vídeos na plataforma. O relatório The Horizon Report, publicado em 2008, apontou que o crescimento de sites de compartilhamento de vídeos e as facilidades de gravação e edição de vídeos motivaram a ampliação da produção de vídeos caseiros voltados para a educação. Vídeos caseiros costumam receber muitas críticas, no entanto, de acordo com Mattar (2009, p. 4):

[...] é preciso superar o receio do uso do vídeo amador em educação, inclusive porque os usuários (nossos alunos) já estão acostumados e sensibilizados com essa nova mídia. Uma cultura de videoclipe, caracterizada pelo consumo frequente de pequenos vídeos e na qual se destaca o YouTube, emergiu na web e precisa ser incorporada às nossas estratégias pedagógicas, inclusive de design instrucional.

Para os professores, uma das funcionalidades mais valorizadas no canal é permitir, por meio da ferramenta Youtube Analytics, o acompanhamento do número de visualizações e do tempo de retenção da atenção de cada vídeo, entre outras informações ali disponíveis. Ou seja, permite-se ao docente saber se o aluno, de fato, assistiu ao vídeo até o final ou não proporcionando uma reflexão acerca do formato e do conteúdo do material ali disponibilizado. Se bem gerida, essa funcionalidade pode representar um ganho significativo numa proposta integrada com as demais estratégias de ensino.

Instituições de ensino investem na construção de canais de videoaulas no Youtube como recursos educacionais abertos (REAs), marcados pela capacidade de reusabilidade de forma legal e podendo ser acessado gratuitamente por qualquer interessado e não apenas por alunos da própria universidade. De acordo com Okada (2011, p.13), os REAs fazem menção ao uso de qualquer material aberto, com licença para utilização, adaptação e compartilhamento com fins educativos revigorando, assim, as práticas educacionais ao permitir compartilhamento de conteúdo sem infração às normas legais. Ou ainda nas palavras de Tori (2016, p.09), permitindo ao professor "fazer uso de diferentes conteúdos e mídias, modificá-los, adaptá-los, criando diferentes percursos e conteúdos" de acordo com as necessidades da instituição e do curso.

Seguindo esse cenário, o setor de vídeo do Consórcio Cederj criou, para cada curso de graduação, um canal no Youtube para a disponibilização das videoaulas. Seguindo a proposta dos REAs, esses materiais estão acessíveis não apenas para os próprios alunos do curso como também para qualquer indivíduo interessado nos temas ali ofertados. Para cada um dos três cursos aqui selecionados para análise (Administração Pública, Tecnólogo em Segurança Pública e Pedagogia) há um canal específico no Youtube com materiais audiovisuais. 


\section{Metodologia e resultados}

Um aspecto relevante no momento do planejamento das videoaulas é a reflexão sobre o tempo de duração de cada um dos materiais. Entre os pesquisadores da área, acreditase que as videoaulas devam ser, preferencialmente, de curta duração, pois há melhor adesão e aderência dos alunos a aulas que não ultrapassem trinta minutos, sendo recomendável produzir vídeos que tenham entre 5 a 15 minutos de duração (BARRÉRE et al., 2011 apud KOUMI, 2006). No caso de conteúdos mais densos e complexos, que exijam mais tempo para serem explicados, recomenda-se dividir o assunto em tópicos, fazendo uma série de vídeos curtos que poderão ser assistidos em sequência pelo aluno. Alguns professores são mais resistentes à gravação de vídeos curtos, por estarem habituados aos 45 ou 50 minutos de aula em sala. No entanto, deve-se atentar para o fato de que a retenção da atenção de um aluno a distância é diferente do aluno presencial justamente pelo seu isolamento físico. Nesse contexto, com o objetivo de ouvir o aluno sobre o tempo mais adequado para uma videoaula provocando reflexões sobre a retenção, formulou-se um questionário com perguntas abertas e fechadas, disponibilizado pelo Google Forms e enviado para todos os alunos inscritos nos cursos de Administração (UFRRJ), Tecnólogo em Segurança Pública (UFF) e Pedagogia (UniRio) atingindo um público estimado de mais de 10.500 discentes. Até o momento, houve o recebimento de 836 respostas chegando-se, dessa forma, aos resultados aqui apresentados.

Entre as indagações feitas junto aos alunos, questionou-se se já haviam passado pela experiência de estudar por meio de videoaulas nas disciplinas já cursadas. De acordo com os resultados, $31,1 \%$ dos entrevistados nunca tiveram acesso a estes materiais até o momento. Já $68,9 \%$ disseram que conhecem o recurso de disciplinas já estudadas em períodos passados. Esse questionamento se fez necessário pois nem todos os cursos oferecidos por meio do Consórcio Cederj oferecem videoaulas já que a iniciativa de incentivar a produção desse tipo de conteúdo é recente na instituição. 


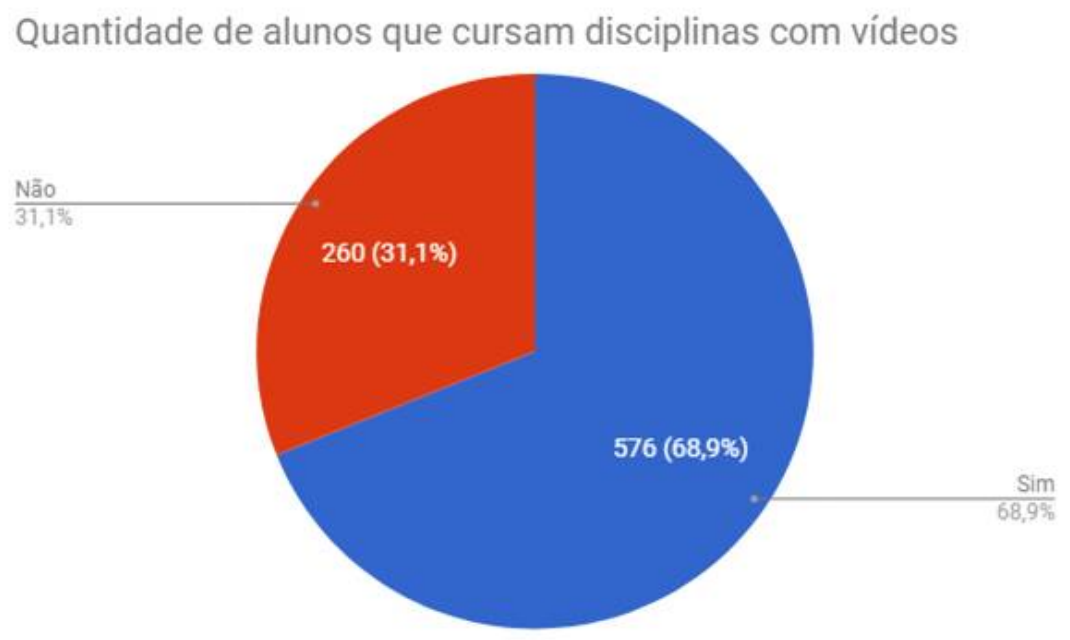

Figura 1 (Quantidade de alunos do Cederj que cursam disciplinas com vídeos)

Em outro questionamento feito, buscou-se compreender qual o tempo mais adequado para a duração de uma videoaula, na opinião dos alunos. O resultado aponta que $31,5 \%$ dos alunos que responderam ao questionário acreditam que o tempo de duração ideal seja o de trinta minutos.

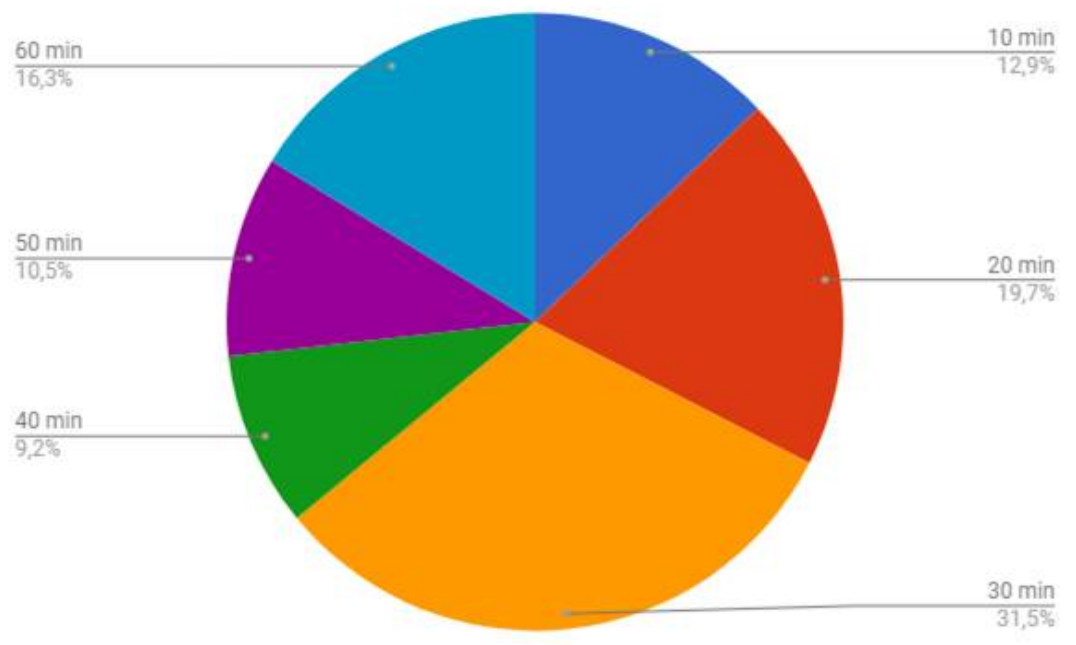

Figura 2 (Tempo ideal de duração de videoaulas, segundo os alunos)

Embora as perguntas abertas não sejam o foco principal deste artigo, vale destacar algumas colocações feitas por discentes sobre o uso de videoaulas. Nesse sentido, muitos falam sobre a preferência por materiais que tragam simulações práticas ou conteúdos complementares a aqueles apresentados nos livros impressos em uma clara referência às videoaulas como materiais de apoio e não como ferramentas principais de estudo - talvez até pelo desconhecimento e pouco acesso a formatos não tradicionais de videoaulas. Muitos também destacam o recurso como um item fundamental no 
estudo de temas mais complexos auxiliando na "fixação do conteúdo", segundo as palavras de um dos alunos entrevistados.

Por meio do acesso aos dados disponíveis no Youtube Analytics dos canais criados para os três cursos aqui analisados, chegou-se a informações sobre a retenção da atenção dos alunos com relação aos vídeos disponibilizados. No canal do curso de Pedagogia (UniRio), onde foram disponibilizados 135 vídeos, o tempo médio de visualização dos materiais é de 6 minutos e 15 segundos. Já no canal do curso de Administração, há 44 vídeos disponibilizados sendo o tempo médio de visualização de 7 minutos e 29 segundos. No canal do curso de Tecnólogo em Segurança Pública, com 20 videoaulas disponibilizadas, esse tempo sobe um pouco chegando a uma média de 9 minutos e 2 segundos. No entanto, vale destacar que, como todas as videoaulas foram disponibilizadas em modo público, qualquer usuário do Youtube pode visualizá-las. A ferramenta Analytics também mostra dados da origem de tráfego dos vídeos, que exibe os meios pelos quais os usuários acessam os materiais. De acordo com esses dados, $44 \%$ dos usuários chegam até as videoaulas do canal do curso de Administração através dos "Vídeos sugeridos", um recurso do próprio Youtube, enquanto apenas 11\% teve origem de tráfego externa. A origem de tráfego externa representa o tráfego de websites que incorporam ou incluem links para seus vídeos no Youtube, que é exatamente o caso dos vídeos do Consórcio Cederj, pois são disponibilizados no ambiente Moodle pela incorporação de seus links. Ou seja, a porcentagem correspondente à origem externa corresponde aos acessos que partem dos links incorporados nas salas de aula virtual do Moodle. Dessa forma, pode-se concluir que nem todas as visualizações são provenientes de alunos do Consórcio, o que pode justificar o fato de o tempo médio de visualização ser ser tão inferior ao tempo de duração de videoaulas que os alunos sugeriram ao responder o questionário.
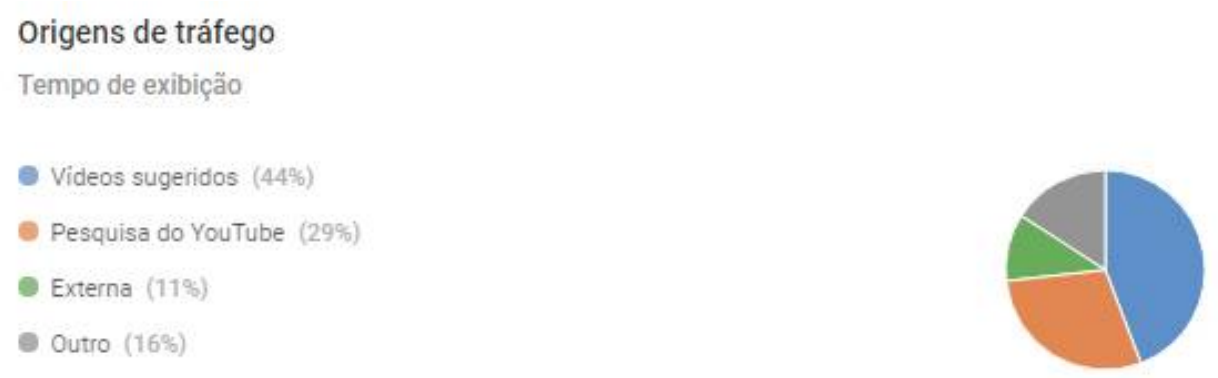

Figura 3 (Origens de tráfego do curso de Administração)

Com relação ao curso de Pedagogia, 47\% dos espectadores chegaram aos vídeos por meio de sugestões do próprio Youtube enquanto $24 \%$ vem por origem externa. 
Origens de tráfego

Tempo de exibição

- Vídeos sugeridos (47\%)

Externa (24\%)

Pesquisa do YouTube (13\%)

Outro (169)

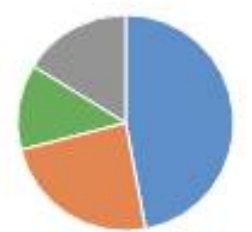

Figura 4 (Origens de tráfego do curso de Pedagogia)

Já no curso de Segurança Pública, 67\% das visualizações têm origem externa, ou seja, por meio de links incorporados no ambiente Moodle, enquanto apenas $8 \%$ chegam por meio da sugestão de vídeos do Youtube. Ainda assim, fica evidente que qualquer usuário do site pode ter acesso aos vídeos produzidos e disponibilizados pela instituição e, por esse motivos, os dados fornecidos pelo Analytics não contabilizam apenas o tempo de visualização dos alunos do consórcio Cederj.
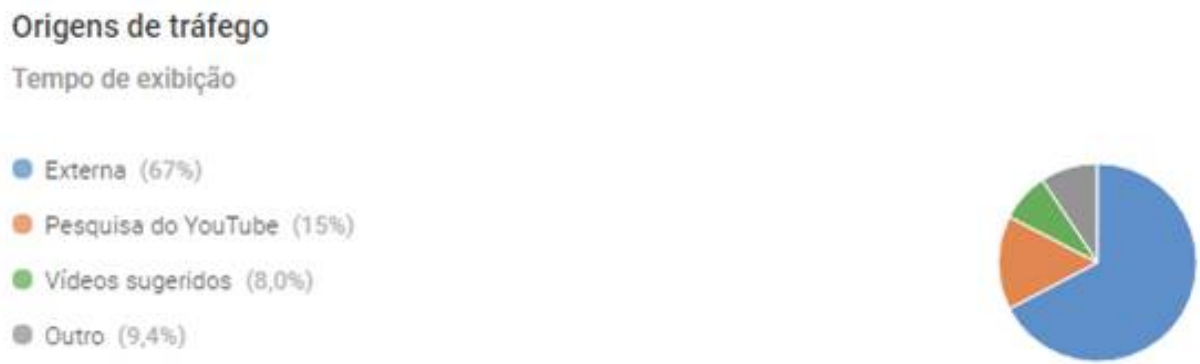

Figura 5 (Origens de tráfego do curso Segurança Pública)

\section{Conclusões}

Mesmo diante dos resultados aferidos em que os discentes defendem o tempo médio de 30 minutos para as videoaulas, acredita-se que o tempo máximo para cada material audiovisual se limite a 15 minutos - podendo ainda ser desmembrado em duas ou três partes. Isso porque um tempo maior de produção associado à solidão ao qual o aluno de EAD convive podem se tornar fatores desmotivacionais para o estudo. Para os casos em que houver maior elaboração e recursos de edição como slides, animações, cortes..., o tempo máximo indicado se encaixa melhor para que o aluno não se submeta a cortes mais rápidos e frenéticos semelhantes aos videoclips. Para os casos mais caseiros em que o foco é apenas a narrativa do docente, não se deve estender a produção a mais de 5 minutos. O tempo máximo de 5 a 15 minutos aproxima-se ainda 
da realidade percebida no Youtube Analytics em termos de retenção sendo o ideal que o discente inicie e termine a exibição do material sem precisar recorrer a interrupções. Quanto ao tempo máximo de 30 minutos indicado pelos alunos para as videoaulas embora o tempo de retenção percebido no Youtube Analytics tenha sido em média de 10 minutos - acredita-se que ainda haja, por parte dos discentes, uma interiorização da duração em média de 50 minutos das aulas presenciais sendo transposta para o ensino online. Sendo assim, o aluno ainda encara os materiais audiovisuais como meros reprodutores da dinâmica das aulas presenciais.

Acredita-se que umas das saídas possíveis seja o investimento na produção de formatos diferenciados de videoaulas que fujam do padrão mais tradicional em que o professor explana um determinado conteúdo, sem a participação e o diálogo com outros atores, sem a inserção de recursos visuais ou sonoros ou sem a interação com os alunos. Quando a videoaula se resume apenas a reproduzir a dinâmica de uma sala de aula, sem o uso de cortes ou de recursos de edição, perde-se grande parte da proposta fundamental de um material audiovisual de explorar a dinamicidade, a agilidade tão características deste tipo de produção. Há produções audiovisuais que se propõem a quebrar justamente com a aridez da mera transmissão de conteúdos e investem no diálogo e na troca com outros professores e/ou alunos em formato de debate, mesaredonda, entrevistas, entre outros. Outra proposta viável seria explorar as demais funcionalidades disponíveis no Youtube já que, além do compartilhamento e da sugestão de vídeos, o site permite a inserção de comentários, monitoramento de popularidade dos vídeos por meio dos likes, além de cartões - ferramenta interativa que promove o aumento do engajamento do espectador - que os professores podem usar nas videoaulas de seus cursos. Se bem geridas, essas inserções podem representar um ganho significativo em atratividade e dinamicidade, agindo de forma integrada com as demais estratégias de ensino e proporcionando, assim, maior retenção da atenção do aluno.

\section{Referências}

BARRERE, E.. Videoaulas: aspectos técnicos, pedagógicos, aplicações e bricolagem. In: NUNES, Maria Augusta Silveira Netto; ROCHA, Elizabeth Matos (Org.). Anais da Jornada de Atualização em Informática na Educação. 1ed. Dourados: EaD-UFGD, v. 1, 2014, p. 70-105.

; SCORTEGAGNA, L.; LÉLIS, C.A.S. Produção de Videoaulas para o Serviço

EDAD da RNP. Departamento de Ciência da Computação Universidade Federal de Juiz de Fora (UFJF) - Juiz de Fora, MG - Brasil. Anais do XXII SBIE - XVII WIE. Aracaju, 21 
a 25 de novembro de 2011 .

DE QUADROS, Claudia Irene et al. Aspectos comunicacionais da educação nas mídias sociais digitais: o caso do YouTube. Ação Midiática-Estudos em Comunicação, Sociedade e Cultura., n. 5, 2013.

KOUMI, J. Designing educational video and multimedia for open flexible learning. Routledge, 1ed, 2006.

MATTAR, João. YouTube na educação: o uso de vídeos em EaD. São Paulo: Universidade Anhembi Morumbi, 2009.

MOORE, M. G. Teoria da Distância Transacional. Revista Brasileira de Aprendizagem Aberta e a Distância, 2002. Disponível em: http://www.abed.org.br/revistacientifica/Revista_PDF_Doc/2002_Teoria_Distancia_Trans acional_Michael_Moore.pdf. Acesso em: 10/09/2016.

OKADA, Alexandra. 16 COMUNIDADES ABERTAS DE PRÁTICA E REDES SOCIAIS DE COAPRENDIZAGEM DA UNESCO. OER and Social Media, p. 176, 2012.

SPANHOL, Greicy Kelli; SPANHOL, Fernando José. Processos de produção de vídeoaula. RENOTE, v. 7, n. 1, 2009.

TORI, Romero. Tecnologia e Metodologia para uma Educação sem Distância. EaD Em Rede-Revista de Educação a Distância, v. 2, n. 2, p. 44-55, 2016.

KENSKI, Vani Moreira (Org.). Design Instrucional para Cursos Online. São Paulo: Editora Senac, 2015.

PRENSKY, M. Digital Native, digital immmigrants. Digital Native immigrants. On the horizon, MCB University Press, Vol. 9, N.5, October, 2001. Disponível em:http://www.m arcprensky.com/writing/Prensky\%20-\%20Digital\%20Natives,\%20Digital\%20Immigrants\% 20-\%20Part1.pdf. Acesso em: 10 de fevereiro de 2018. 